\title{
Corporate Governance Issues: Disclosure and Transparency. An Interdisciplinary Approach
}

\author{
Christian Zhelev \\ $\mathrm{PhD}$, University of National and World Economy, Bulgaria
}

\section{Abstract}

Two of the pillars of contemporary corporate governance are examined in this article - disclosure and transparency. Though an interdisciplinary approach, knowledge from different fields of the economic science are brought together in order better clarify the interdependence and the level of interaction between these. Knowledge traditionally considered to be part of the Corporate Governance (disclosure and transparency and what is most modern nowadays - ESG) is examined form the perspective of the governance bodies and other stakeholders, taking into account tools from the fields of sustainable development, project management and marketing. The processes of digitalization also find their reflection in the current article. The case study approach is used to illustrate the interdisciplinary interaction.

Keywords: corporate governance, disclosure, transparency, ECG

\section{Introduction}

Nowadays corporate governance (CG) is considered to be inseparable part of the company's performance and results. The vast interest in CG from international institutions and policymakers is a proof that CG matters. Academia is not lagging behind. In the recent years plenty of authors deal with CG. This permeant interest is one more illustration of its importance and relevance.

In this article disclosure and transparency are the main issues which is tried to be shed light on. Through the methods of induction and deduction, literature review and case study, it is argued that disclosure and transparency is a key principles of CG that has interdisciplinary nature. That is why the interdisciplinary interactions between CG and other scientific branches is a subject of the analysis. 


\section{Corporate governance - scope defined}

In order to better understand the pillars of contemporary corporate governance, especially the ones the article is focused on (disclosure and transparency), we should have the basic understanding what actually it is. Many definitions have been provided, many members of academia strive to provide such definitions so that they could subordinate the existing knowledge to their own understanding. Paraphrasing Huse (2000), his understanding could be summed up as follows: corporate governance can be defined as the set of interactions between internal and external stakeholders of the company and the corporate governance bodies that direct the company. Demb \& Neubauer (1992) state that corporate governance is a managerial process by which corporations take into account the rights and preferences of stakeholders. Another group of authors ( Corbetta (2001), Gnan \& Montermerlo (2001) and many others) define corporate governance in a similar way. According to them basically the essence of CG is: how companies are directed and controlled, but this understanding can no longer be successfully applied in the current situation. It would be precise in case further explanation is provided. By adding "CG is also the set of formal and informal relationships between corporate executives, senior management of the company, shareholders and other relevant stakeholders" to the above-mentioned definition we could clarify the matter; only in this way we could reflect the shift of CG from inside the company to society at large.

The diversity of perspectives on the problems in the existing knowledge regarding corporate governance definitions leads to different definitions. In the current article, another of the well-recognized definitions shall be provided, followed by an author's interpretation.

Indisputably, OECD provides this one understanding of what corporate governance is. Namely: Good corporate governance helps to build an environment of trust, transparency and accountability necessary for fostering long-term investment, financial stability and business integrity, thereby supporting stronger growth and more inclusive societies ${ }^{1}$.

Led by this understanding, in this article, a further light on the matter is shed.

Deriving from OECD's definition, also taking into account and the other definitions mentioned and not mentioned in the preceding lines, another understandings of corporate governance is provided here. It serves the established goals and objectives of the study. That is why the proposed definition is: "Corporate governance can be represented as an inverted pyramid that balances at its top, and the foundation of this pyramid is the governing body of the corporation."

Figure 1. Corporate governance - pyramidal presentation

\footnotetext{
${ }^{1}$ http://www.oecd.org/corporate/
} 


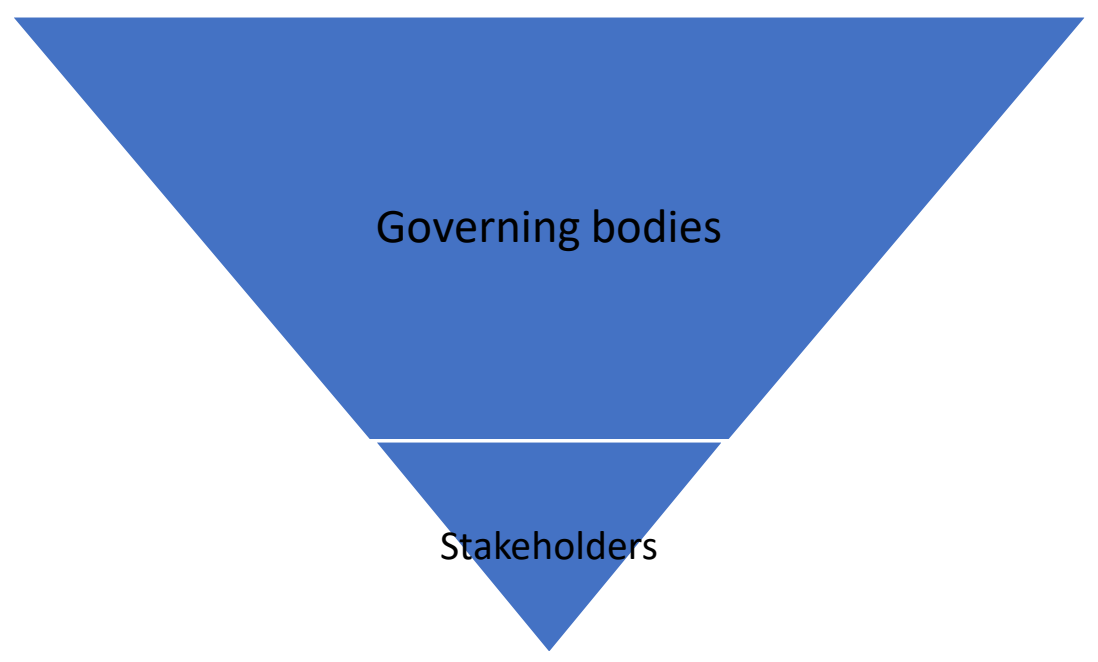

Source: The author, based on his $\mathrm{PhD}$ thesis.

This thin balance could tilt the entire pyramid easily. The balance is the key in the proposed understanding of what contemporary corporate governance is. Namely the governing bodies are responsible for this balance, because (as it is well known), they are responsible for giving the strategic direction of the organization.

More arguments in support of this definition could be added here. They could be summed up as follows:

Corporate executives are representatives of the owners. In the face of a representative democracy, they express the interests of those who have aired them to run their property;

Corporate executives are the ones who set the path for the development of the company;

They balance the interests of different stakeholders by:

- being responsible for enhancing shareholder wealth;

- caring for the society as a whole;

- being responsible for creating customer satisfaction mechanisms for the company.

Provide suitable conditions for building effective relationships with suppliers, creditors, etc.;

Finally - they are the ones who are also responsible for the successes and failures of the company.

This understanding is also driven by the fact that in the triad (owners, company managers / corporate executives/governing bodies) the key role of the corporate 
executives is in directing companies in their relationship with various stakeholders, including stakeholders form the international markets. In addition, CG is seen as an effective synergy of this triad, for the purposes of disclosure and transparency, especially in the field of sustainable development. The role of corporate governance working in the interests of shareholders and stakeholders cannot be left in the background as well. It is evident that disclosure and transparency play key roles in the relationships of the organization with the various stakeholders, at least because poor disclosure would lead to information asymmetry, which is something highly undesirable, especially in the digital society today.

\section{Selected theories supporting the understanding of the importance of the role of disclosure and transparency in CG}

There is a vast availability of theories that deal with Corporate governance ${ }^{1}$.The various authors strive to prove that the theoretical foundations of what we call CG today. This could be traced even at the beginning of the manifestation of economic relations between the subjects in the economic system. Such searching may have its reasons, but it is unlikely such explicit links and interdependencies to be deduced in this case. That is why, in this section the article shall not focus on those theories. More or less, interdisciplinary theories shall be discussed in order to better outline the searched interactions.

\subsection{The Firm as a Nexus of Contracts}

The nexus of contracts theory depicts the firm in a network of implicit and explicit contracts with stakeholders; however, the shareholder has predominance over other stakeholders. The boards and management continue to have a fiduciary responsibility to maximize shareholder value. The firm as a nexus of contracts describes the firm in relation to its environment-a view of the firm looking outward into its environment. This is the useful moment is support of the main goals and objectives of the current paper. Moreover, well recognized economists such as Michael Jensen and William Meckling as well as Frank Easterbrook are considered to be the developers of this theory.

\subsection{Resource Dependence Theory}

Resource dependence theory provides a similar view. It also describes power dependence in the relationships between the firm and other actors in its environment and focuses primary attention to those stakeholders in the environment who have the greatest impact on the profitability of the firm. According to some authors, the basic notion of resource dependence theory is the need for environmental linkages between the company and outside resources. In this perspective, directors connect the firm with external factors by choosing the resources needed to survive (Pfeffer

\footnotetext{
${ }^{1}$ The fundamental theories that have formed the contemporary CG over the years are consider as well illuminated in the literature. That is why here theories such as Principal - Agent, stewardship theory etc. are not mentioned in the paper. As it was mentioned, the idea here is to see the interdisciplinary interaction by providing theoretical and empirical knowledge from other fields of the economic science.
} 
and Salancik, 1978). Consequently, boards of directors serve as an important instrument for receiving critical elements of environmental uncertainty into the firm. Environmental linkages or network governance could reduce transaction costs related with environmental interdependency. The organization's need to require resources and these leads to creation of relationships or network governance between organizations. Additionally, the uneven distribution of needed resources results in interdependence in organizational relationships. Several factors would appear to intensify the character of this dependence, e.g. the importance of the resource(s), the relative shortage of the resource(s) and the extent to which the resource(s) is concentrated in the environment.

Moreover, governance bodies can serve to link the external resources with the firm to overcome uncertainty and managing effectively uncertainty is critical for the existence of the company. According to the resource dependency rule, the directors bring valuable resources like skills, information, key constituents (suppliers, buyers, public policy decision makers, social groups). Thus, it is considered that the potential outcome of connecting the firm with external environmental factors and reducing uncertainty can decrease the transaction cost.

\subsection{Stakeholders theory}

According to the research design, it is appropriate to point out the next theory recognized by an even wider range of economic disciplines, in order to find the interaction there by tracing different stages of the evolution of the views in this theory.

We will start with Coleman (2008), who states that the initial interpretation of the stakeholders theory is too narrow because it presents shareholders as the only stakeholders. However, it better explains the role of corporate governance because it emphasizes a different way of building a business. A review of the theory confirms that this is so, but on the other hand, we cannot ignore even the initial stages of this theory. This is where the focus is placed on the rights of shareholders and the performance of fiduciary duties by the management of the company (corporate management). And the fulfillment of fiduciary obligations is also in the foundation of "company laws.

Of interest here is the critique of Jensen (2001). He states that the success of the organization is not only about contributing to the stakeholders, and in no case can it be measured alone. There are other key elements such as information flows from corporate executives, relationships between people within the organization, work environment, etc. that are vital and must be kept in mind.

This stakeholder theory in its contemporary understanding includes the wide range of individuals the company encounters in its operations. From the perspective of CG, we can say that this theory reflects the dynamics, modernity and new players that corporate governance and stakeholders are considering and developing. 
Given that it is central to contemporary corporate governance theories, it makes sense to look at how stakeholders are classified and what stakeholder management policies can be taken.

It is well known, that the basic stakeholder classification, derived directly from the theoretical formulation, is that of internal and external to the company. Internal are the shareholders, corporate executives and employees of the company. While external are suppliers, creditors, government, pressure groups, etc. that are relevant or can in any way affect the business of the company.

Another classification scheme put the stakeholder question that way: consubstantial, contractual and contextual. It is important to mention that, not only stakeholders can be judged in terms of their affiliation with the company environment, but it must also be emphasized in terms of their importance to the company, because the company cannot treat them in one and the same way.

\subsection{The Project Management Institute and stakeholders}

The Project Management Institute (PMI) offers an instrument (The Power Interest Grid), which is typally used in the project management field of knowledge, but keeping in mind the interdisciplinary approach and also the fact that this instrument is used outside the area of project management, it could be applied in the article as a beneficial one as well. What is more - empirical checks have probed its relevance to the matter discussed.

Aa stated on the website of PMI "the Power Interest Grid, which is also known as the Power Interest Matrix, is a simple tool that helps you categorize project stakeholders with increasing power and interest in the project. This tool helps you focus on the key stakeholders who can make or break your project. In turn, this helps you in stakeholder prioritization."

Figure 1. The Power Interest Matrix

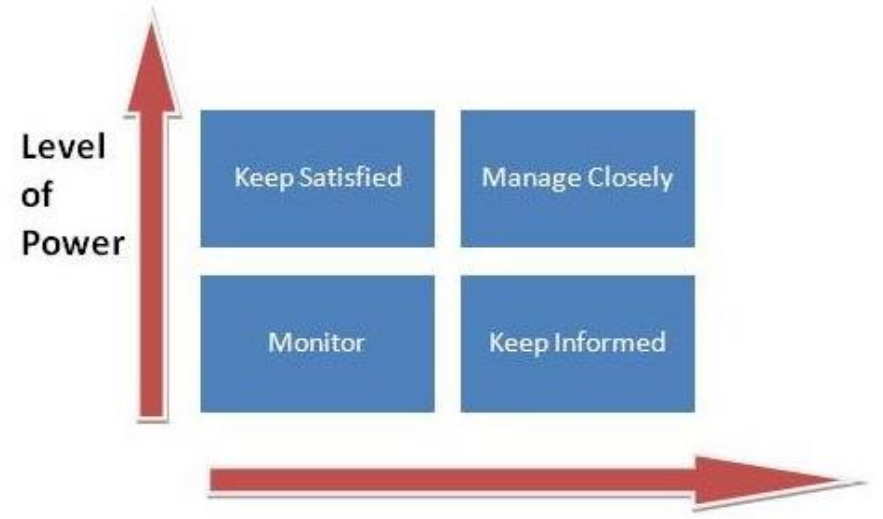

Level of Interest 
Source: https://www.brighthubpm.com/

This instrument will help the governance bodies to prioritize their policy concerning stakeholder management and could also provide them with meaningful insight for further reaction in the disclosure and transparency area.

\section{The OECD/G20 Principles of Corporate Governance (2015)}

The Principles could be defined as the pillars of contemporary corporate governance, because they are a fundamental document for countries that have adopted these principles as a guideline for developing CG codes. They, together with the White Papers, lay the foundation for a solid frame for what is known as good corporate governance. On the following lines, an attempt will be made to schematically compare the principle "disclosure and transperancy" with the previously mentioned theoretical statements.

Disclosure and transparency according to the OECD Principles ${ }^{1}$

Their last revision of the principles, from 2015, defines the key areas of disclosure and transparency in point $\mathrm{V}^{2}$ of the document.

The corporate governance framework should ensure that timely and accurate disclosure is made on all material matters regarding the corporation, including the financial situation, performance, ownership, and governance of the company...Disclosure requirements are not expected to place unreasonable administrative or cost burdens on enterprises... Experience shows that disclosure can also be a powerful tool for influencing the behaviour of companies and for protecting investors. A strong disclosure regime can help to attract capital and maintain confidence in the capital markets. By contrast, weak disclosure and non-transparent practices can contribute to unethical behaviour and to a loss of market integrity at great cost, not just to the company and its shareholders but also to the economy as a whole. Disclosure also helps improve public understanding of the structure and activities of enterprises, corporate policies and performance with respect to environmental and ethical standards, and companies' relationships with the communities in which they operate.

But what are the main areas of the disclosure and transparency principle? They are defined in depth in the principle, that's why here only key moments are marked:

Table 1. Principle V - Disclosure and Transperancy

A. Disclosure should include, but not be limited to, material information on:

1. The financial and operating results of the company.

\footnotetext{
${ }^{1}$ The following point is driven out directly form the principles of corporate governance OECD/G20 2015. Author's comments follow the listing.

${ }^{2}$ Only certain moments of the principle are presented. This approach aim to serve the objectives of the article.
} 
2. Company objectives and non-financial information.

3. Major share ownership, including beneficial owners, and voting rights.

4. Remuneration of members of the board and key executives.

5. Information about board members, including their qualifications, the selection process, other company directorships and whether they are regarded as independent by the board.

6. Related party transactions.

7. Foreseeable risk factors.

8. Issues regarding employees and other stakeholders.

9. Governance structures and policies, including the content of any corporate governance code or policy and the process by which it is implemented.

C. An annual audit should be conducted by an independent, competent and qualified, auditor in accordance with high-quality auditing standards in order to provide an external and objective assurance to the board and shareholders that the financial statements fairly represent the financial position and performance of the company in all material respects.

D. External auditors should be accountable to the shareholders and owe a duty to the company to exercise due professional care in the conduct of the audit.

E. Channels for disseminating information should provide for equal, timely and cost-efficient access to relevant information by users.

Source: OECD, Principles of Corporate Governance (2015)

Basically in the table above we could easily trace the interaction of the principles with the theoretical framework, discussed in the previous section. The stakeholders are evidently present, what is more with the new edition of the principles the new moment - disclosure of non -financial information is explicitly present. The companies should disclose such information as well. This new moment widens the scope of the corporate governance, deepens its interdisciplinary nature and bridges the gap to what is known as interdisciplinary approach. There are authors (Boeva, Zhivkova, 2017; Boeva, 2019) who examine these interdisciplinary interactions from the prospective of sustainable development, global supply chain management, ESG disclosure and so on. According to Boeva and Zhivkova (Boeva, Zhivkova, 2017)The return rates of the companies' share and the dividends are no longer the only thing that matters for the managers. For different reasons they incorporate the sustainable development policy, in all its three dimensions, into the corporate governance. Most of the companies nowadays have developed a corporate social responsibility policy and make quite a lot of efforts to communicate it to the public. The most popular aspect of the sustainable development is the environmental pillar. The cited authors 
also state that in the area of ESG disclosure: Responsible investment relies on the ability or the prerequisite for achieving long-turn and sustainable returns based on the acceptance and compliance of the environment protection policies, establishment of effective social system and governance. Following such policy of responsible investing means that there already is a new approach to analysis, investment decisions and engagement of the shareholders ${ }^{1}$. Boeva in her book "Capital, Melting Glaciers and $2^{\circ} \mathrm{C}^{\prime \prime}$ (Boeva, 2019) also makes a fundamental analysis of the role of ESG disclosure in the disclosure and transparency policy of the contemporary companies. What is more, according to an article from Concordia University: Firms that value and practice environmental transparency in their reporting to stakeholders are in general better economic performers than those whose practices are more opaque.

It is evident that the disclosure and transparency principle put a challenge in front of the companies, but this challenge, if successfully managed with, should serve in favor of their long run development in a sustainable way, with the interests of the stakeholders in mind.

It is worth mentioning here who are the best companies in Europe according to "Ethical Boardroom", pointed as winners in complying with the corporate governance principles. Because this classification is with a leading indicator disclosure.

Table 2. Corporate Governance Winners 2019 - Europe

Engineering

Automotive

Insurance

Financial Services

Transportation \& Logistics

Aerospace \& Defence

Utilities

Leisure \& Hospitality

Oil \& Gas

Beverage

Conglomerate

Pharmaceuticals

Telecommunications
Schneider Electric SE

Volvo Group

Allianz SE

Barclays Bank PLC

Deutsche Post DHL Group AG

Leonardo S.p.A.

Iberdrola S.A.

TUI AG

Royal Dutch Shell PLC

Diageo PLC

Nestlé S.A.

Sanofi S.A.

Teléfonica S.A. 
Source:

https://ethicalboardroom.com/corporate-governance-winners-2019europe/

As it can be seen these are companies from various sectors, but the compliance with the principles has provided them not only with awards. A quick check of their annual reports and their capital market presence confirms that good disclosure and transparency put the company on a relevant future strategic path. What is more, all the companies comply with the principles and disclose information on regular babes.

The big auditing companies also underline the importance of further disclosure. According to a PwC publication: in addition to financial information, organizations should disclose policies relating to business ethics, the environment and other public policy commitments, as this information can be important to investors and others in better evaluating the relationships between companies and the communities in which they operate. Deloitte offer the disclosure and transparency checklist, form which is obvious the necessity of the companies not only to disclose financial but also social and governance information.

\section{Case study: Nestle vs Greenpeace from another angle}

So far the good examples and the trendsetters were pointed out. The case study presented below shows the consequences of untimely / poor disclosure and lack of transparency and the potential undesirable outcomes for the company.

According to official information in Financial Times on March 17 2010, environmental group Greenpeace launched a social media attack on Nestlé's Kit Kat brand vie video in YouTube. Greenpeace had found that Nestlé was sourcing palm oil from Sinar Mas, an Indonesian supplier that it claimed was acting unsustainably. Nestlé said it used only 0.7 per cent of global palm oil. Nestlé's initial response was to force the video's withdrawal from YouTube, citing copyright. This led to enormous social media buzz. The lesson, according to FT is: showing leadership on sustainability is becoming a business imperative. A sustainability risk is potentially big when the whole world can find out about it overnight.

The conclusion, proposed by FT corresponds to the initial tasks and objectives of the current article if the disclosure ad transparency principle is applied What is more to be added here is the reaction of the capital markets. One more result from the scandal was the drop of Nestlé's share prices.

The thorough investigation of case study presents a solid ground for some conclusions:

The interdisciplinary interactions are evident, including interactions Marketing Corporate Governance;

The rightfulness of the thesis of ESG disclosure is once more confirmed; 
The need for integrated approach in the field of disclosure and transparency is obvious;

Timely disclosure is a must for the contemporary corporation.

Companies can no longer rely on being non-transparent in front of the various publics;

The proper managing of different stakeholders is required, because the potential power and interest of those stakeholders should not be underestimated.

\section{Conclusion}

In the current article the main focus was on disclosure and transparency as one of the pillars of contemporary corporate governance. The investigation of the problem was executed within the assumption of the possibility for applying interdisciplinary approach. The proposed theoretical framework, together with the case study, proved the possibility of applying such an approach. Once again, the basic understating of the author that such collaboration of the different fields of knowledge is possible was confirmed.

In the light of CG, disclosure and transparency the importance of the timely, effective, and ongoing disclosure was confirmed, because the poor disclosure leads to undesirable effect for the long run performance of the companies and not only. Because according to OECD insufficient or unclear information may hamper the ability of the markets to function, increase the cost of capital and result in a poor allocation of resources. And this statement sets a fruitful ground for further research.

\section{References}

[1] Baker, E. (2012). Planning effective stakeholder management strategies to do the same thing! Paper presented at PMI@ Global Congress 2012-North America, Vancouver, British Columbia, Canada. Newtown Square, PA: Project Management Institute.

[2] Boeva, Bistra (2019) , Capital, Melting Glaciers and $2^{\circ} \mathrm{C}$, Iztok - Zapad

[3] Boeva, Bistra; Zhivkova, Stela; Stoychev, Ivan (2017). Corporate Governance and the Sustainable Development. European Journal of Economics and Business Studies

[4] Coleman, Anthony. (2008). Corporate governance and firm performance in Africa: A dynamic panel data analysis. Journal for Studies in Economics and Econometrics. 32. 1-24.

[5] Corbetta, G., and D. Montemerlo (1999). "Ownership, Governance and Management Issues in Small and Medium Sized Family Businesses: A Comparison of Italy and the United States," Family Business Review XII(4), 361-374.

[6] Demb, Ada \& Neubauer, F.. (1992). The Corporate Board: Confronting the Paradoxes. 10.1016/0024-6301(93)90307-2. 
[7] Gnan, L. \& Montemerlo, D. 2001. Structure and Dynamics of Ownership, Governance and Strategy: Role of Family and Impact on Performance in Italian SMEs. In G. Corbetta \& D. Montemerlo (Eds.), The Role of Family in FamilyBusiness: 224-244. F.B.N. Research Forum Proceedings, Rome, Italy.

[8] Huse, M. 2000. Boards of directors in SMEs: A review and research agenda. Entrepreneurship \& Regional Development, 12: 271-290

[9] Jensen, Michael C. (2000) Value Maximization, Stakeholder Theory, and the Corporate Objective Function. European Financial Management Review, N. 7, 2001, HBS Press

[10] OECD. (2015). OECD Principles of Corporate Governance.

[11] Pfeffer, J. and Salancik, G. (1978), "The External Control of Organizations", New York: Harper \& Row

[12] https://singapore-academy.org/index.php/en/education/researchconsulting/library/item/350-corporate-governance-disclosure-andtransparency

[13] https://www.sciencedaily.com/releases/2019/04/190418131246.htm

[14] https://www2.deloitte.com/global/en.html

[15] https://www.oecd.org/daf/ca/corporate-governance-factbook.pdf

[16] https://www.oecd.org/

[17] https://www.ft.com/content/90dbff8a-3aea-11e2-b3f0-00144feabdc0 